\title{
Responding to COVID-19: Contextual, Pedagogical, and Experiential Considerations from Canadian Northern Postsecondary Educators
}

\author{
Kerry Lynn Durnford, ${ }^{1,2}$ Kim Lemky, ${ }^{3}$ Pertice Moffitt, ${ }^{4}$ Perez Oyugi, ${ }^{5}$ Kathie Pender, ${ }^{1}$ \\ Tammy Soanes-White ${ }^{3}$ and Gloria Bott ${ }^{1}$
}

(Received 13 July 2020; accepted in revised form 16 November 2020)

\begin{abstract}
The COVID-19 pandemic forced the closure of face-to-face classes in a northern Canadian college in March 2020. Educators and staff went into rapid response mode to continue teaching and supporting students from a distance. Critical reflections were written by the authors to summarize their responses to teaching and learning during the early phases of the pandemic. These reflections were themed, considered individually and collectively, then analyzed and synthesized. In this paper, critical reflection is used as an educational process within the context of critical constructivism and transformative paradigms. We share how teaching during the pandemic solidified our commitment to students and cemented our critical pedagogy by thinking and acting critically to assist students with this disruption in their education. Equipped with these capabilities, educators are empowered to work with students to problem solve and transform our educative lives for a just society. An inter-professional opportunity across programs, spurred by the pandemic, meets organizational strategic directions and fosters a promising relationality. Increased territorial and local technological supports and internal professional development is needed to solidify the immense prospects for distance education as the College transitions to a polytechnic university.
\end{abstract}

Key words: educational response; COVID-19; technology-enabled teaching and learning; critical constructivism; determinism; circumpolar; Canadian Arctic; reflection; postsecondary; lived experience

RÉSUMÉ. La pandémie de la COVID-19 a entraîné l'arrêt des cours en personne d'un collège du Nord canadien en mars 2020. Les éducateurs et le personnel sont passés en mode d'intervention rapide pour assurer la continuité de l'enseignement et soutenir les étudiants à distance. Les auteurs ont exprimé leurs réflexions critiques afin de résumer leurs interventions en matière d'enseignement et d'apprentissage pendant les premières phases de la pandémie. Ces réflexions ont été classées par thèmes, considérées individuellement et collectivement, puis analysées et synthétisées. Dans cet article, la réflexion critique est employée à titre de processus éducatif dans le contexte du constructivisme critique et des paradigmes de la transformation. Nous faisons ressortir le fait que la façon dont l'enseignement a été dispensé durant la pandémie a permis de solidifier notre engagement envers les étudiants et renforcé notre pédagogie critique par le biais de réflexions et d'actions critiques pour aider les étudiants à faire face à cette perturbation scolaire. Grâce à ces capacités, les éducateurs sont outillés pour travailler avec les étudiants afin de résoudre des problèmes et de transformer nos vies éducatives en vue d'une société juste. Une occasion interprofessionnelle entre les programmes, stimulée par la pandémie, satisfait les orientations stratégiques organisationnelles et favorise une relationnalité prometteuse. Il faut du soutien technologique accru à l'échelle locale et territoriale et du perfectionnement professionnel interne pour solidifier les immenses possibilités de l'enseignement à distance pendant que le collège fait la transition vers une université polytechnique.

Mots clés : réponse pédagogique; COVID-19; enseignement et apprentissage à l'aide de la technologie; constructivisme critique; déterminisme; circumpolaire; Arctique canadien; réflexion; postsecondaire; expérience vécue

Traduit pour la revue Arctic par Nicole Giguère.

\footnotetext{
${ }^{1}$ School of Health \& Human Services, Bag 9700, 5004 - 54th Street, Yellowknife, Northwest Territories X1A 2R3, Canada

${ }^{2}$ Corresponding author: kdurnford@auroracollege.nt.ca

${ }^{3}$ School of Business \& Leadership, Bag 9700, 5004 - 54th Street, Yellowknife, Northwest Territories X1A 2R3, Canada

${ }^{4}$ Aurora Research Institute, Bag 9700, 5004 - 54th Street, Yellowknife, Northwest Territories X1A 2R3, Canada

${ }^{5}$ Student Services Division, Bag 9700, 5004 - 54th Street, Yellowknife, Northwest Territories X1A 2R3, Canada

(C) The Arctic Institute of North America
} 


\section{INTRODUCTION}

The coronavirus disease (COVID-19) pandemic impacts the lives of students, educators, and staff around the world through interrupting valued education and learning, transforming teaching and learning platforms, and adjusting to these implementations. Other current experiences of the evolving pandemic include a disruption to postsecondary students' learning and career trajectories, a loss of in-person graduation celebrations, physical distancing from peers and colleagues, self-isolation, and converting homes to work settings. These responses are at an educational level but many more responses are personal, familial, community, and societal and intersect with the educational contexts of our lives, resulting in upheaval in the world as we know it. The purpose of this paper is to share the educational response to the initial phases of the pandemic as experienced by postsecondary educators in northern Canada using critical constructivism theory, humanism, and determinism. We examine our response through a conceptual model, focused literature review, personal reflections from each of the authors, and highlight recommendations and implications moving forward.

\section{BACKGROUND}

In late December 2019, the novel coronavirus emerged in Wuhan, China (GC, 2020). The unpredictability of COVID19 symptoms fueled widespread dissemination of the virus globally and resulted in a need for emergency public health containment measures. The subsequent declaration of a global pandemic indefinitely altered the trajectory of normalcy as we know it. Although northern Canada is sparsely populated and isolated from the rest of Canada, the announcement of a territorial state of emergency in mid-March 2020 amplified the reality of COVID-19 for Northerners (GNWT, 2020). The mandate to close public buildings, work and learn from home, and social distance further compounded the isolation related to harsh winters and frigid temperatures.

Employed at a college in Canada's North, we are positioned as either educators or administrators at one campus. This postsecondary institution is decentralized with three main campuses, 22 community learning centres, and a student population of more than 3000 full- and parttime students. The college is situated on traditional lands of First Nations, Inuit, and Métis peoples, who comprise just over $50 \%$ of the territory's population (NWT Bureau of Statistics, 2017). With strong roots and expertise in adult basic education, the college enacts a traditional face-to-face pedagogical approach in some programs and a blended approach in others. The college supports development of northern people and communities and, to that end, is evolving to a polytechnic university. The recommendation to transform the college to a polytechnic university is the response to a recent foundational review of the college commissioned by the Minister of Education, Culture and Employment (MNP LPP, 2018). The findings from this review generated six key themes: governance, accountability, academic program management, operations, and student recruitment and retention (for more information see MNP LPP, 2018). Actions emanating from this recommendation informed operational imperatives before COVID-19. The recommendation also underlies actions taken by educators and staff as they worked with students to navigate teaching and learning challenges brought about by the pandemic. The college quickly launched into an emergency remote teaching and learning approach, while attempting to maintain the necessary relational practices that are the foundation of northern remote higher education experiences. Planning for the polytechnic university continues as the pandemic evolves.

\section{CONCEPTUAL FRAMEWORK}

The philosophical assumptions that guide our teaching and learning practices remain the same as pre-pandemic and revolve around three concepts: critical constructivism, humanism, technology and determinism. These broad concepts were deemed useful for analyzing conceptual, experiential, and pedagogical practices during the pandemic, including underlying relations to broader concepts and lived experiences of educators, staff, and students.

\section{Critical Constructivism}

Critical constructivism focuses on developing an understanding and disposition about knowledge that furthers democracy, equity, and inclusion (Bentley, 2003; Mertens, 2003; Kincheloe, 2005). This focus means that knowledge is co-constructed in an environment of co-learning. Educators and students use a participatory approach to explore topics through inquiry and interpretation. There is freedom to express individual thought that both contributes and contests ideologies and generates new knowledge at both the individual and group levels.

Critical constructivism, based on constructivism, suggests that individuals build and construct their meanings in everyday settings (Bentley, 2003; Mertens, 2003; Kincheloe, 2005). With this theory, knowledge acquisition honours the contribution of experiences, observations, and other lifeways. Educators use critical constructivism and constructivism as embedded philosophies and learning theories in traditional classrooms, distance learning, and virtual classrooms. Teaching and learning literature support these theories (Bentley, 2003; Kincheloe, 2005; Legg et al., 2009; Brandon and All, 2010; Decelle, 2016; Clark, 2018).

In the current pedagogical shift from face-to-face spaces to virtual or online spaces, we continue to frame our teaching and learning processes from a critical constructivist perspective. However, we do this with a new 
intention. Using a critical constructivist lens ensures that educators and students engage in creating, interpreting, acting, and reflecting on knowledge in individual ways unique to their experiences and contexts. The co-creator (the educator) of the learning experience facilitates a learning environment that motivates self-direction and interaction from a distance. This also involves the educator creating and facilitating a social presence or "the degree to which learners feel socially and emotionally connected with others in an online environment" (Cleveland-Innes and Campbell, 2012:272) within an environment that promotes knowing, being, and doing in virtual spaces.

The pandemic resulted in an abrupt change and a steep learning curve for both students and educators. This learning included fostering a social presence while learning and applying technology, as well as promoting and sustaining teaching and learning activities. The use of critical constructivism has the potential to expand educator and student perspectives to include broader concepts and lived experiences. Specifically, this sudden shift from faceto-face delivery to delivery via technology provides an opportunity to intertwine teaching practices with liberating pedagogies, problematize the nature of reality and knowledge, and reflect on emancipatory ideals of critical theory (Kincheloe, 2005) along with humanizing theory (Cox-Davenport, 2014). Meaning that although the learning has changed, the philosophical underpinnings of critical constructivism can still guide educational adaptations while simultaneously contributing to a better world.

\section{Humanism, Technology, and Determinism}

Our transition to online learning provides an opportunity to consider our relationship with more than one philosophical perspective, for example, humanism, technology, and determinism (Kanuka, 2008). CoxDavenport (2014) illuminates humanization as the core concept in a grounded theory study exploring the way educators create and develop effective social presence. Cox-Davenport (2014) also highlights the facilitation of an online climate that enables student relationships as one of several best practices. To foster those positive relationships, the educator needs to be student-centred and consider the transition of the student to the new technology along with opportunities for interactions. Researchers describe this transition as moving from "enduring to enjoying" through several phases that include "virtual paralysis, engagement, getting into it, and surprised enjoyment" (Giddings et al., 2006:262). Launching the online format requires consideration of these phases by the educator in course planning, implementation, and evaluation processes. Students need instruction and support with technology. Thus, incorporating humanism allows us to observe how students and educators transition to a new educational norm, including paying attention to issues such as endurance, frustration, and enjoyment as individuals enact social presence.

Humanism, technology, and social determinism intersects with critical constructivism in several ways. Selecting a philosophy of technology that aligns with a humanistic orientation emphasizes students' growth and development as a primary focus in the learning environment. Flexibility in adopting and adapting a technological interface consistent with teaching and learning approaches invites rather than restricts access, equity, and inclusion (Bates, 2015). Determinism focuses on technology choices and their application as tools that serve teaching and learning objectives and extend the capabilities of learners necessary for higher education in remote spaces (Kanuka, 2008). Through technology-enabled practices and a humanism lens, educators are better positioned to meet relational needs of students using online interactions that promote diversity, reflective practices, and independent learning. Garrison and Akyol (2015) also argue that interdependence is necessary when co-construction is incorporated in meaningful learning, whereas ClevelandInnes and Campbell (2012) emphasize emotional presence as an alignment between social constructivism and familiar technological applications. When co-construction is operating to its fullest, this activity inspires deep learning, facilitates social presence, encourages student engagement, and aligns with cultural relevance.

Technology as described by Bates (2015) refers to tools and practices that are accessible and appropriate for the students. Elaborating, Bates (2015) contends that technology and an intentional application in design, production, utilization, and evaluation of tools and platforms for teaching and learning support and elevates student learning and invite inclusion for all students in response to their learning needs. The philosophy of technology therefore inspires right-technology action and orientates technological practices that help students acquire, understand, and synthesize knowledge. Considering our own unique situation in northern Canada, its diverse cultural context, resources, and tools available, and educator and student preparedness for a quick transition at this time, a technological lens is helpful for elucidating educational strategies deployed during the pandemic.

\section{LITERATURE REVIEW}

Pandemics and other disasters impact higher education (Davis et al., 2004; Feast and Bretag, 2005; Marshall et al., 2020; Torres et al., 2020) and much of this impact remains unknown as the pandemic evolves and literature expands. In remote and northern locations, issues related to technology and the rapid shift to online learning, equity and inclusion, and relationality are important for understanding contextual, experiential, and pedagogical considerations deployed during the pandemic. 


\section{Technology and Online Learning}

Technological strategies provide promising educational delivery alternatives during the pandemic. The use of technology has the potential to reduce situational barriers for students (Bates, 2005), enhance access to education (Moisey and Hughes, 2008; Marshall et al., 2020), and expand educational possibilities beyond traditional practices and experiences (Bates, 2015; Long, 2017). The pandemic has led to an exponential increase in the use of technology to ensure learning and education continue uninterrupted.

Technology in teaching and learning has a 10 - to 20 -year history and is considered a standard educational solution with asynchronous and synchronous options (Long, 2017). Despite this history and awareness of the linkages between student success and technology use (Long, 2017), educators and students continue to experience challenges in online learning environments (Anderson, 2008; McNamee et al., 2020). For example, there are concerns that some students struggle with the lack of guidance inherent in online learning (Long, 2017). There are also concerns with bandwidth constraints, which can limit an educator's ability to discover student preconceptions and cultural perspectives, including presenting a limited view of student body language and other "paralinguistic clues" (Anderson, 2008:47). Other concerns with e-learning technologies (i.e., the use of electronic resources for learning) are related to perceptions that the online learning environment perpetuates other forms of "cultural colonization" based on curricula that mimic the cognitive style of experts and an extension of dominant knowledge (Kanuka, 2008:101). The use of technology as an educational tool should therefore take into account social and historical forces that shape and are shaped by the very technologies used (Anderson, 2008; Kanuka, 2008). Similarly, because dropout rates are higher in learning environments where e-learning culture has not taken root and because of the lack of high-touch strategies, where an educator responds to student cues or face-to-face queries (Long, 2017), scholars recommend proceeding with caution to ensure scaffolding of technology from simple to more complex so that there is an ease of positive adjustment and capability (Bates, 2015).

With the use of technology to deliver learning, educational institutions are increasingly called upon to implement approaches for supporting students. These supports are in addition to online tools and technology. Echoing these sentiments, Moisey and Hughes (2008) contend that online learning requires a constellation of flexible, accessible, and readily available supports to promote students' independence while facilitating learning. They include cultivating caring relationships and fostering collaboration (Long, 2017). Moisey and Hughes (2008) also refer to metacognitive supports or providing supports that enhance students' ability to study online as well as their ability to access and retain knowledge. Moisey and Hughes (2008:427) note that metacognitive supports increase "student confidence, reduce stress, and enhance their learning experience."

The United Nations Human Rights Council (2016) officially recognized the importance of adequate broadband and access to the internet to all people. The United Nations adopted a resolution "the promotion, protection and enjoyment of human rights on the internet" in 2016. It states that access to the internet is a human right that must be protected (UN Human Rights Council, 2016). The resolution recognizes that the internet facilitates opportunities that can benefit peoples' lives, including education. The resolution further states that the rights people have offline should apply on the internet (regarding safety and security), and acknowledges that there is unequal access in developing versus developed countries, and that women have less access to the internet than men (UN Human Rights Council, 2016).

Closer to home, a connectivity strategy is in place that recognizes that lack of internet access in rural and remote communities limits the ability of these communities to participate in the Canadian and global economy (GC, 2019). Authors of the strategy also identified that students have to consider internet speed to plan and complete homework (GC, 2019). The strategy endorses a commitment to increasing access to high-speed connectivity in rural and remote communities (including 190 Indigenous communities) to ensure that they can fully engage in the Canadian and global economy. More specifically, the government's goals are for $90 \%$ of Canadians to have access by $2021,95 \%$ by 2026 , and $100 \%$ by 2030 in the hardest to reach areas (GC, 2019). The strategy further identified that only $24 \%$ of households in Indigenous communities have access to high speed (50/10 Mbps) (GC, 2019). Students enrolled at the college faced challenges adapting to studying from home, as some students did not have access to high speed internet and or were unable to access reliable internet in their communities.

In the NWT, residents identify that although internet speed has improved, it is still not strong enough because of the absence of fibre optic lines. Currently, the local provider in isolated communities has installed satellites (Malbeuf, 2018). Even the NWT's largest city, Yellowknife, has regular disruptions to internet service for a variety of reasons (Malbeuf, 2018; Williams, 2019). To further address the impacts of COVID-19, the local internet provider doubled internet usage caps in satellite communities and waived data overage fees for residential customers (McBride, 2020).

From the foregoing, it is vital for educators and students to have access to technology. It is also vital for technological strategies to align with the philosophical stance of students, educators, and the institution if technology is to provide congruence and consistency in educational spaces. Additionally, educators and administrators must ask themselves: Why do we use technology? Does its use serve the needs of student learning? Does its use merit deep learning and support student engagement and 
success? Using the right technology expands educational possibilities beyond traditional practices and experiences.

\section{Equity and Inclusion}

Critical constructivism provides a bridge between constructivist ideologies and critical epistemology by centering notions of equity and inclusion in educational practices. Elaborating on equity and inclusion terminologies, equity in education refers to a condition or state of fair, inclusive, and respectful treatment of all students whereas inclusion refers to acceptance, being included in a group, and having access to the same opportunities and resources as all students (Ontario Ministry of Education, 2009). These terminologies rest on a value system that incorporates principles of social justice and concepts such as fairness, equality, and human rights. Extended to teaching and learning practices, these concepts (equity and inclusion) revolve around learning environments, learning opportunities, and the provision of supports necessary for learners to succeed (GNWT, 2016).

Postsecondary educational practices linked to equity and inclusion help students to secure social and personal successes in life (Preston, 2008). Within this context, equity and inclusion are not only central to achieving high-quality education but are key to the development of inclusive societies (UNESCO, 2008) and the creation of a just society, as envisioned in the Canadian Charter of Rights and Freedoms (Gomes, 2008).

When considering the northern context of the college, it is vital to ensure that efforts to address equity and inclusion do not reinforce inequity (Tamik and Guenter, 2019). Therefore, the educational imperative of equity and inclusion provides an entry point for us to interrogate educational practices and strategies deployed during the COVID-19 pandemic to ensure they do not reinforce inequity. Take for example the use of the term "student." Although used for readability in this paper, it presents contradictions when juxtaposed to equity and inclusion ideals related to considerations of power and privilege. For many students and educators, distance learning is new, thus in its newness, it makes this form of learning more equitable with the realization that students and educators are all learning together.

The historical impact of intergenerational trauma related to residential schooling has created a distrust of the Western education system (Makokis, 2009; Ross et al., 2015; TRCC, 2015). This dissonance with education systems and a renewed understanding of consequences of intergenerational trauma foster acts of reconciliation whereby educators focus on building trust and joy, mutuality, and reciprocity in teaching and learning. This emphasis now includes attention to an online community of inquiry, where social teaching and cognitive presence are all necessitated and enacted (Garrison et al., 2001). There is a need to create inclusive environments that are culturally safe for all students and educators to heal from the effects of historical trauma.
Purposeful equity and inclusion in our pedagogy are an act of reconciliation. As a responsible educational institution, implementation of the Truth and Reconciliation Commission of Canada's (2015) Calls to Action is a priority to honour current and past Indigenous students, Elders, educators, and staff. The college further emphasizes its commitment to Indigenous education through signing the Indigenous Education Protocol (Colleges \& Institutes Canada, 2015). The Protocol establishes the unique learning environment and people required to support Indigenous education. Pidgeon (2016) postulates a transformative organization that leaves Indigenous students empowered and educates non-Indigenous people to the unique cultures, learning, and history of Indigenous peoples. Attempts to live the Protocol present a challenge for colleges and higher education institutions (Gaudry and Lorenz, 2018) and are compounded by the additional vulnerabilities that have resulted in teaching and learning environments under COVID-19. The future establishment of a polytechnic university calls for endorsement of Indigenous expertise funneling throughout the organization to alter curricula and policies to reflect a reconciliation of worldview disparities.

The current pandemic exacerbates unequal educational experiences as students and educators find themselves in circumstances that engender increased uncertainties in teaching and learning situations (Weimer, 2020). These uncertainties create unintended and disproportionate consequences for people living in vulnerable circumstances (Canadian Human Rights Commission, 2020), including inequities brought about by experiences of colonial oppression, intergenerational trauma, poverty, and gender inequality. For example, more than $70 \%$ of students at our college self-identify as Indigenous, and these students are predominantly female. Many students in northern and remote communities experience technological issues such as low bandwidth and exorbitant connectivity costs (NNSL Staff, 2019). Achievement is a concern if the students cannot meaningfully connect.

Against this backdrop, equity and inclusion issues are pervasive when students cannot resolve issues they encounter with technology or cannot finish their courses because they lack funds or live in communities with connectivity issues. Because of these contextual issues, the vulnerabilities for Indigenous students are compounded as the pandemic evolves. Not only will the students contend with challenges related to distance learning but they must address other issues that inform their lived experiences. Here, we must consider the risk to vulnerable communities during a second wave of COVID-19 and if, for example, food rationing or limited supplies and resources are available to only some in our population. According to Jeffery (2020), there are ethical principles that must be addressed: transparency, health benefit, efficiency, and adaptability. Educators and senior leadership must reexamine their critical role in ensuring equity and inclusion (Chun and Evans, 2018; Tamtik and Guenter, 2019) as they envision new teaching and learning norms during and after the pandemic. 


\section{Relationality}

Students and graduates of the college frequently speak of educator-student relationships as essential to their persistence and success. As a key component of caring, relationality involves the formation and cultivation of intentional relationships (Porr and Egan, 2013). In transformative education processes, relationality is perceived as vital in a socially just world (Lange, 2018). Lange advises that relationality moves us to consider the interdependence of all living things one upon the other and the dynamic nature of our existence. This interdependence has long been expressed by Indigenous peoples in their relationship to the land. Relationality requires trust and is reflected in Indigenous ways of being and knowing (Nutton et al., 2020). There is a parallel between relationality and the culturally safe classroom that encourages both faculty and student to reach to each other in socially just and equitable ways; this in turn contributes to a sense of belonging (Bamford and Pollard, 2018). When belonging occurs in this way, becoming and transforming are achieved. This attention to relationality is particularly important for educational institutions with diverse student populations.

Factors such as the remote geographical location of the college and small student numbers enable relationality; however, the purposeful and intentional commitment to coming to know the students solidifies the college as a caring and relational institution. Because of our relationality, we are ethically responsible for each other (Butler, 2015; Jeffery, 2020). We are responsible for creating learning environments that encourage trust, caring, and respect, but within that we must move beyond traditional ethics to consider relational ethics (Jeffery, 2020). Jeffery describes relational ethics that are of particular importance during COVID-19, for example, relational autonomy moves beyond individuals to encompass the social context in which they live. This context has a significant impact on the learning abilities of the student in an online environment.

\section{METHODOLOGY}

Critical reflection is a research method, an educational process, and a key characteristic of qualitative research (Schön, 1987; Brookfield, 1995; Morley, 2008; Creswell, 2014). As a process, critical reflection is useful for illuminating the relationship between actions, consequences, and possible solutions (Brookfield, 1995; Morley, 2014). Our starting point for critical reflection was an individual critique of the effects of the COVID-19 pandemic on our educational practice. The process evolved to include reflection-in-action, review of the published literature, and adjustments to practice (Schön, 1987; Brookfield, 1995).

In this paper, critical constructivism and transformative paradigms underpin our reflections to highlight educational practices and relationships as well as to intertwine teaching practices with liberating pedagogies (Brookfield, 1995; Bentley, 2003; Mertens, 2003; Kinchloe, 2005). Within these philosophical underpinnings, critical reflection was used to elucidate a problematic situation within the context of northern and remote learning. As faculty or administration, we submitted written critical reflections of our response to teaching and learning during the COVID-19 pandemic. The reflections are themed, considered individually and collectively, then analyzed and synthesized.

\section{PERSONAL REFLECTIONS ON EDUCATIONAL STRATEGIES DURING COVID-19}

To eliminate repetitiveness in sharing the reflections, we included comments related to the adjustment of transitioning from the classroom to online learning. This transition required creativity, offered challenges, and highlighted inequities within the student population. Commonalities found amongst our reflections included limited bandwidth issues, adaptive practices, and rapid responses. Innovative supports and practices were necessary.

\section{Chaos for Students and Educators (Durnford)}

Our students are worried. What does this mean for their education? Will they graduate on time? We worry about them; we hope decisions made by our leadership will allow us to continue to teach. In the meantime, in the absence of a professional development or higher education learning centre, but with remote information technology support, we begin instructing ourselves and mentoring each other in virtual platforms from which to deliver classes, offer simulations, as well as, hold asynchronous and synchronous discussions to promote learning consolidation. We want this to work and we work hard. We are faced with responsibilities beyond our job descriptions, but the students remain our focus. We turn to our colleagues who have experience teaching remotely, whose work is little known and celebrated. Perhaps this is an opportunity for our stakeholders to realize just how resilient, skilled, and ingenious this small group of educational leaders really are, which may fan the flame for an expanded future of higher education in the North.

\section{Creating Community (Pender)}

In order to retain the collegial environment established since September, continued program delivery was the only option. The main obstacle was converting a program that thrives on face-to-face relational engagement to one that is completely online. The desire of students to express continuance to learn and change to achieve educational mandates is admirable. This captive audience refreshes our motivation to provide unique programming that is 
engaging and purposeful. The strength of the educators has carried programming. The absence of casual conversations and coffee breaks fuels the reliance on social media to connect through contemporary platforms. Students were accustomed to visit offices for advice or were comforted knowing the educators' open doors were welcome refuges for discussion. The pandemic has acknowledged community is an asset to survival. Re-creating the state of the previous interactive community is exasperating and rewarding. The new community is evolving as we learn to adapt to the confines and constructions of our online reality.

\section{Blended Learning (Soanes-White)}

We were the lucky ones. Because of past funding cutbacks, we had moved to a blended format and had combined student contact with video conferencing almost a decade ago. Our blended approach to teaching and learning was already familiar to both our students and faculty but this was a new level of blending for us. Moving exclusively online meant combining the best of what we had learned from a conferenced environment to a virtual one. The most important aspect of this experience was ensuring the continued importance of relational practices with students, regardless of their location. We wanted as few disruptions as possible, while providing the highest quality of student experience possible.

Although the pandemic closed our physical classrooms, we were quick to adapt. We continued to use Moodle as a learning management system and moved our video conference classes onto a virtual synchronous platform. We extended every connection possible including phone, texting, online conferencing, face time, and messaging. However, as students went back to their home communities, many inequities still existed such as no access to computers, bandwidth issues, and no childcare for homebound children. These compounding factors led to higher than normal rates of attrition and my wish for normalcy in our connection with students again.

\section{Adaptability (Lemky)}

Classes comprised weekly three-hour synchronous sessions. I weighed the options of continuing to lecture or to move completely online with Moodle (the course management software students were most familiar with). I chose a path for student completion that worked within the constraints of an off-campus work environment. I contacted students through Moodle and through email to share a completion path for each course. Students often had to share computers with their children and were unable to meet regularly in class. I did not continue to lecture but instead recorded short audio clips to accompany written assignment instructions. I encouraged students to work with me on a one-on-one basis. To gauge students' learning outcomes, I removed the synchronous exam component and instead opted for reflective assignments, with which they were already comfortable. Further, I provided my cell number and met with students at their convenience. Although these strategies worked for some students, other students were reluctant to use these alternatives; many who did not have these options chose instead (in many cases, reluctantly) to challenge the courses again in 2021.

\section{Connecting the Dots with Technology (Oyugi)}

COVID-19 has drastically changed the way I think about the strategies needed to support student success and how we work together. For example, in teams made up of faculty, management, and other individuals representing the postsecondary sector, we discussed the supports students needed to complete their semester and strategized on how to connect the dots between technology, learning, and support networks. Specific processes to resolve the technology challenge for students started with educators submitting lists of students who required computers and internet access to continue with their studies. The college then worked with the government and other partners to secure computer donations. Once computer donations arrived, I worked closely with the information technology services team and the students to determine if needs had changed and if there were other issues to be resolved prior to computer pick up. Similarly, the student services team rolled out an online tutoring program and closely collaborated with other campuses to ensure students were helped irrespective of their campus location. Counsellors and housing support staff were issued with telephone devices and computers so that they could continue to provide support to students remotely. Moving forward, a cross-campus team of educators and support staff will help in the delivery of foundational courses in Moodle, the use of Microsoft (MS) Teams, basic life skills, and academic supports from remote locations. The changes brought about by COVID-19 have propelled the tutoring and support teams to enhance their own proficiency in using MS Teams, Moodle and other social network platforms while paying close attention to how our use of synchronous or asynchronous interactions make it possible for our students to continue their learning journey.

\section{Work-Life Balance (Bott)}

When the pandemic was declared, I found myself in a dichotomy. On the one hand, I was overjoyed at the chance opportunity to challenge the routines and norms of work and those of family life. On the other hand, the chaos had me pining for the return of those routines and norms.

I continue to find myself considering a similar yet slightly reframed dichotomy. That is, the pandemic has elucidated possibilities for innovative and enhanced teaching and learning as well as improved work-life balance opportunities for postsecondary students and educators alike. However, the changes may also be setting some precedents that reinforce systemic norms and 
further disadvantage certain populations. For example, socioeconomic status and gender can have implications for education and employment; students and educators are impacted.

I believe the possibility of progress is a positive byproduct of the pandemic for not only the college but also for the broader higher education community at large. It is my hope for the future that only the best thinking and practices about teaching and learning will prevail and sustain. Critical examination of power cannot be dismissed with that end in view.

\section{Adapting Research (Moffitt)}

As a northern researcher, I was forced to cancel faceto-face interviews and moved instead to telephone or video interviewing. This method of data collection works well with some participants but others, such as Indigenous Elders, grounded in oral tradition and storytelling in what can be described as traditional practices of intimate and personal ways, did not wish to engage in this manner for such sensitive research as domestic homicide. In domestic violence research, safety for the research participant is heightened; as a researcher, it is difficult to maintain safety when the participant is miles away on a telephone and retribution or stigma may occur by speaking out.

However, through observation of community response and commentary to COVID-19 in the media (another source of data), the contributions and adaptability of local people to a new format of storytelling occurred. Many stories focus on the fear that the coronavirus brings and local experience of past disease outbreaks. The resilience of local people is palpable today as Elders bring their stories of past epidemics, describe the lessons learned, and share their traditional knowledge in new and meaningful ways. This resilience reconfirms culture as a dynamic process and validates our awareness of the potentiality of human beings to critically respond to the influences on their existence in society. By working with community in data collection and all steps of the research process during the pandemic, validity and accuracy of the contextual experience and response will be better recorded and relationships enhanced. I realize it is not the time to suspend our research activity but a time to foster and enable relationships, albeit through physical distancing, and these efforts will provide meaningful results.

\section{DISCUSSION}

Two major themes emerged from the reflections. A predominant theme from the educators and staff narratives is ingenuity. A second notable theme is related to supports for students, educators, and staff. Starting with ingenuity, narratives by faculty support the notion that the pandemic nurtured ingenuity, which evolved from the teaching and learning skills, knowledge, and experiences of educators and students. This result is in keeping with a core principle of critical constructivism. As noted by Nowicka-Sauer et al. (2018), new knowledge is formulated from what we know and experience and is contextually and culturally constructed. Educators are experienced teachers grounded in critical constructivist assumptions whereby the students and their experiences are central to our teaching and learning modalities. In addition, the reflections show that students used their knowledge and experience to respond to their new teaching and learning environment. In the Nowicka-Sauer et al. (2018) study, albeit with patients, students brought unique knowledge and experience along with them, including their new online learning experience. As educators, we tapped into students' unique strengths and challenges to create online classrooms with the students co-producing an environment that motivates and engages them.

Furthermore, faculty spoke of their concern and worry for students, and their commitment to quality curricula in a time of crisis. Similarly, in our response to the pandemic, despite working from home and the physical distance between educators and staff, intentional efforts to connect and provide support reaffirmed the commitment of the college to caring and relationality. These intentional efforts were also strengthened through the development of online caring relationships (e.g., mentors), collaborations within and across teams, and ongoing communication. However, in terms of relational ethics, these reflections do not offer glimpses into the dilemmas the educators and students faced nor the ethical principles that helped them with their decision-making to resolve issues that occurred.

Turning to student supports, the change from face-toface delivery to online and distance learning amplified existing inequities. Most students at the college identify as Indigenous. As such, online and distance learning amplified inequities tied to "inadequate financial resources, poor academic preparation, lack of self-confidence and motivation, [and] absence of role models who have postsecondary education experience" (Restoule et al., 2013:1). Moreover, the students who needed computers, internet access, and housing support to continue with their studies were mainly Indigenous. These students also required digital empowerment and fluency to maximize their chances of success (Butler-Henderson and Crawford, 2020) and support with mental health issues. These underlying inequities will not disappear after the current pandemicinduced emergency postsecondary educational mode is over.

Student supports were critical during the transition. As the narratives reveal, the college took steps to secure used computers for students. Student residences remained open for those unable to return to their home communities. Staff within the student support division made changes to counselling and student success services by incorporating technology in their delivery framework. The administration provided regular information on mental health and emphasized the importance of self 
care and other supports within the community. These supports allude to individual and institutional openness to alternative approaches in order to ensure student success. Specifically, the supports confirm Long's (2017) assertion that institutions must develop supports that focus on the student, learning, and improved performance, in addition to technology. Additionally, these supports allude to individual and institutional practices centered on transition considerations, such as student technological requirements and metacognitive supports (Moisey and Hughes, 2008), along with a choice of platforms that would provide opportunities for interactions. Together, these practices can ensure greater access and can further educational goals that are centered on democracy, equity, and inclusion (Bentley, 2003; Mertens, 2003; Kincheloe, 2005).

The reflections confirm that during educational transitions, educators and staff need additional support, assistance, and training in order to fundamentally change how they deliver programs. Although this transition from face-to-face to distance and online delivery happened during a pandemic, the reflections also indicate that with the right support, educators and staff can quickly and successfully transform their pedagogical approaches. These experiences mirror those of other postsecondary institutions (Bao, 2020; Johnson et al., 2020; Leigh et al., 2020). Education of students that mandates hands-on experiences for learning and evaluation provides another complicated angle. There has been a flurry of activity in the published body of health education literature since the start of the COVID-19 pandemic addressing the unique requirements to educate and graduate students in health programs; while short-term solutions are achieved, longerterm planning to meet in-person learning requirements is demanding. The transition during the pandemic also provoked creativity for educators and staff, both individually or in teams through processes of reflexivity on knowledge unique to their experiences and contexts, which is vital in critical constructivist approaches to education.

One of the greatest strengths for which the college educators are well known is small class sizes with close instructor educator-student relationships. The increased mental health needs of students from the uncertainty and stress of their new normal, coupled with historical trauma experienced from the intergenerational impact of the residential school experience in the North (Gone, 2013) mean that educators not only teach, but are also advisors, advocates, and support providers. Suddenly, students who struggled to reach out in person when classes were on campus were now at greater risk of being unsuccessful. In their attempts to quickly move courses to quality online platforms, educators faced the added concern of ensuring students remained motivated, connected, and safe. This issue has similarly been described in the literature by Patel (2020). Educators committed to ensuring the largely pervasive open-door policy that existed on campus remained virtually open. The strength of long-held collaborative partnerships with other southern universities allowed educators to dialogue about pedagogical approaches and best practices in a digital world and to share resources and professional development opportunities. These approaches are aligned with Bao's (2020) principles around effective delivery and sufficient support, which include online tutoring, email guidance, and contingency educational planning during the COVID-19 pandemic. However, given the emergency nature of the transition, it is unclear from the reflections how educators created and facilitated a social presence or how knowledge was co-created with students in online platforms.

As educators, we set out to reflect on our experiences. These experiences position online education as a new normal that mirrors crisis efforts, adds responsibilities to learn new technology, demands increased knowledge, fuels the search for teaching and learning alternatives, and elucidates possibilities for innovation in teaching, learning, and research. These reflections provide a glimpse into the great responsibility put on the shoulders of individual educators to transition their courses to distance and online delivery and to learn the new technology, and for students to quickly adapt to the new normal. Educators without prior online teaching experience were also expected to transition quickly to online platforms, which Bates (2020) contends is acceptable as a short-term emergency strategy. However, these expectations assume that students and educators are able to train themselves, and that each person is equally positioned to transition to online teaching and learning even when presented with other challenges such as additional child care, Elder care, mental health, and homeschooling responsibilities (Brabazon, 2020). Therefore, in our eyes, students, educators, and the college have, to date, triumphed in the face of unsurmountable odds and during a very stressful time.

\section{RECOMMENDATIONS FOR THEORY, PRACTICE, AND RESEARCH}

Our individual reflections highlight equitable access to technology as paramount for student success and show that many institutions and educators are still striving to understand this new educational landscape. Therefore, to address issues of technological inequity, educators and institutions such as the college must continue to advocate that territorial decision makers prioritize funding for access to reliable bandwidth and digital learning modalities across the Canadian North. This includes advocating for universal and low-cost internet access for education (Bates, 2020) and for access to digital technology and remote education to be subsidized at a federal level to address this national inequity. Furthermore, increasing technology access supports the calls to action of the Truth and Reconciliation Commission of Canada (2015) by creating equitable access to education for Indigenous students.

Equity and inclusion in education are often promised in policies but are persistently inadequate for the realities 
that present themselves. As a result, we recommend that targeted supports must be considered in order to positively impact student success. In addition, we encourage educators to interrogate institutional and pedagogical practices to ensure that their practices and plans do not reinforce inequity (Tamtik and Guenther, 2019) and we echo calls for educators to advocate for strategies that enable rather than hinder equal access (Bates, 2020). This advocacy includes paying attention to barriers that arise when institutions download responsibilities and costs to students, some of whose lived realities are informed by systemic marginalization. As well, health care students are entering their professions at a time of risk and liability for frontline workers who, with heightened personal risk, are obligated to care for others. As suggested by Jeffery (2020), it will be important for educators to hear students' stories and dilemmas, support them, and assist students in decision-making to keep them safe.

The COVID-19 pandemic highlights the need for additional services as the college transitions to a polytechnic university. The need for a funded centre of teaching and learning is paramount to ensuring educator development and the creation of quality teaching materials. Therefore, we call for the development of institutionwide faculty development programs and the development of a strategy and plan for digital learning, as well as as models for choosing appropriate technologies for learning, training, and resources for faculty (Bates, 2020). Additional human resources in the areas of information technology, admissions and registration, counselling, and library and information services are necessary to ensure educators can focus on teaching and research.

The use of technology to deliver education also relates to communication. Although not a major aspect of this paper, it is important to twin these issues. Because of additional challenges related to implementing online education, educators and administrators are encouraged to simplify communication delivery to reduce confusion and possibly frustration. For example, implementing a didactical communication process among students, faculty, and staff builds knowledge co-construction, especially during emergency situations. This process includes the provision of timely information in order to allow students to plan their personal and educational lives, as well as operationalize and evaluate their online learning experiences.

This is an opportune time to challenge the current view of distance learning by calling for decolonizing standard online delivery, creating a sense of community, and understanding how to engage Indigenous students who require the support of Indigenous advisors (Pidgeon, 2016). There is also a need for educators and staff to ensure that their pedagogical choices incorporate diversity, allow students to meaningfully engage with the content, and incorporate diverse ways for students to demonstrate their learning. Finally, formative and summative evaluation and responsive feedback must be prioritized at this time to tailor quality programming that is supportive of all students.
There are implications for research, evaluation, and education going forward. The abrupt spread of the coronavirus, the disruption of services, and the interventions of social distancing and quarantine are all topics to explore in greater detail. Researchers may want to explore, through a variety of methods, the impact on colleges, educators, students, and administrators. There may be insight provided by investigating governance and leadership before, during and after the pandemic. For programs that involve clinical work, the rapid transition of new graduates in the time of the pandemic may produce knowledge that is vital for emergency preparedness. As well, inquiry related to the interventions used and put aside by the college leadership may shed light on preparedness for a similar occurrence in the future. In addition, follow up to pedagogies of relationality through an account of ethical dilemmas and the ethical process to solve these dilemmas may generate knowledge to be used with future emergencies.

\section{CONCLUSION}

In this paper, we have shared the response of northern Canadian postsecondary educators to the early phases of the COVID-19 pandemic. Reflections about our responses to the pandemic provide an account that can be reexamined in subsequent and expected waves of the pandemic. Our documented journeys, philosophical perspectives, and recommendations may assist with future emergency preparedness by postsecondary institutions.

\section{REFERENCES}

Anderson, T. 2008. Towards a theory of online learning. In: Anderson, T., ed. The theory and practice of online learning. Edmonton, Alberta: AU Press. 45-74.

Bamford, J., and Pollard, L. 2018. Developing relationality and student belonging: The need for building cosmopolitan engagement in undergraduate communities. London Review of Education 16(2):214-227.

https://doi.org/10.18546/LRE.16.2.03

Bao, W. 2020. COVID-19 and online teaching in higher education: A case study of Peking University. Human Behavior and Emerging Technologies 2(2):113-115.

https://doi.org/10.1002/hbe2.191

Bates, A.W. 2005. Technology, e-learning and distance education, 2nd ed. Abingdon, Oxon, England: Routledge.

- 2015. Teaching in a digital age: Guidelines for designing teaching and learning. Vancouver, British Columbia: Tony Bates Associates.

, moderator. 2020. What should we be doing about online learning when social distancing ends?

https://www.tonybates.ca/2020/04/07/what-should-we-bedoing-about-online-learning-when-social-distancing-ends/ 
Bentley, M.L. 2003. Introducing critical constructivism. Paper presented at the annual meeting of the American Educational Studies Association, 29 October-2 November 2003, Mexico City, Mexico.

https://web.utk.edu/ mbentle1/Crit_Constrc_AESA_03.pdf

Brabazon, H. 2020. The academy's neoliberal response to COVID-19: Why faculty should be wary and how we can push back. Academic Matters online.

https:/academicmatters.ca/neoliberal-response-to-covid-19/

Brandon, A.F., and All, A.C. 2010. Constructivism theory analysis and application to curricula. Nursing Education Perspectives 31(2):89-92.

Brookfield, S.D. 1995. Becoming a critically reflective teacher. San Francisco, California: Jossey-Bass.

Butler, J. 2015. Notes towards a performative theory of assembly. London, England: Harvard University Press.

Butler-Henderson, K., and Crawford, J. 2020. Digitally empowered students through teacher leadership: The role of authentic leadership. Journal of Applied Learning \& Teaching 3(sp. iss. 1):88-96. https://doi.org/10.37074/jalt.2020.3.s1.6

Canadian Human Rights Commission. 2020. Statement Inequality amplified by COVID-19 crisis.

https://www.chrc-ccdp.gc.ca/eng/content/statementinequality-amplified-covid-19-crisis

Chun, E., and Evans, A. 2018. Leading a diversity culture shift in higher education: Comprehensive organizational learning strategies. Abingdon, Oxon, England: Routledge.

Clark, K.R. 2018. Learning theories: Constructivism. Radiologic Technology 90(2):180-182.

http://www.radiologictechnology.org/content/90/2/180.extract

Cleveland-Innes, M., and Campbell, P. 2012. Emotional presence, learning, and the online learning environment. The International Review of Research in Open and Distributed Learning13(4):269-292. https://doi.org/10.19173/irrodl.v13i4.1234

Colleges \& Institutes Canada. 2015. Indigenous education protocol for colleges and institutes.

https://www.collegesinstitutes.ca/policyfocus/indigenouslearners/protocol/

Cox-Davenport, R.A. 2014. A grounded theory of faculty's use of humanization to create online course climate. Journal of Holistic Nursing 32(1):16-24. https://doi.org/10.1177/0898010113499201

Creswell, J.W. 2014. Research design: Qualitative, quantitative and mixed methods approaches. Los Angeles, California: Sage.

Davis, D., Ryan, D., Sibbald, G., Rachlis, A., Davies, S., Manchul, L., and Parikh, S. 2004. Severe acute respiratory syndrome and the delivery of continuing medical education: Case study from Toronto. Journal of Continuing Education in the Health Professions 24(2):76-81. https://doi.org/10.1002/chp.1340240204

Decelle, G. 2016. Andragogy: A fundamental principle of online education for nursing. Journal of Best Practices in Health Professions Diversity: Education, Research and Policy 9(2):1263-1273.
Feast, V., and Bretag, T. 2005. Responding to crises in transnational education: New challenges for higher education. Higher Education Research \& Development 24(1):63-78. https://doi.org/10.1080/0729436052000318578

Garrison, D.R., and Akyol, Z. 2015. Thinking collaboratively in educational environments: Shared metacognition and coregulation in communities of inquiry. In: Lock, J., Redmond, P., and Danaher, P.A., eds. Educational developments, practices and effectiveness. London: Palgrave Macmillan.

https://doi.org/10.1057/9781137469939_3

Garrison, D.R., Anderson, T., and Archer, W. 2001. Critical thinking, cognitive presence, and computer conferencing in distance education. American Journal of Distance Education 15(1):7-23. https://doi.org/10.1080/08923640109527071mkra

Gaudry, A., and Lorenz, D. 2018. Indigenization as inclusion, reconciliation, and decolonization: Navigating the different visions for indigenizing the Canadian Academy. AlterNative: An International Journal of Indigenous Peoples 14(3):218-227. https://doi.org/0.1177/1177180118785382

GC (Government of Canada). 2019. High-speed access for all: Canada's connectivity strategy. Ottawa, Ontario: Innovation, Science and Economic Development Canada. https://www.ic.gc.ca/eic/site/139.nsf/eng/h_00002.html

. 2020. Coronavirus disease (COVIID-19): Outbreak update. Ottawa, Ontario: GC.

https://www.canada.ca/en/public-health/services/ diseases/2019-novel-coronavirus-infection.html\#a4

Giddings, L.S., Campbell, S., and Maclaren, P. 2006. Going online to learn health sciences research methods. The student experience. Australian Journal of Educational Technology 22(2):251-267.

https://doi.org/10.14742/ajet.1301

GNWT (Government of the Northwest Territories). 2016. Guidelines for inclusive schooling: Supporting the NWT ministerial directive on inclusive schooling.

https://www.ece.gov.nt.ca/sites/ece/files/resources/inclusivesc hoolingmanualandguidelines-educatorversion-english.pdf

2020. News release: Public health emergency declared in the Northwest Territories.

https://www.gov.nt.ca/en/newsroom/news-release-publichealth-emergency-declared-northwest-territories

Gomes, M. 2008. Creating an equitable and inclusive institution: Discussion paper. Nanaimo, British Columbia: Vancouver Island University.

http://adm.viu.ca/sites/default/files/viu-creating-an-equitableand-inclusive-institution.pdf

Gone, J.P. 2013. Redressing First Nations historical trauma: Theorizing mechanisms for Indigenous culture as mental health treatment. Transcultural Psychiatry 50(5):683-706. https://doi.org/10.1177/1363461513487669

Jeffery, D.I. 2020. Relational ethical approaches to COVID-19 pandemic. Journal of Medical Ethics 46(8):495-498. https://doi.org/10.1136/medethics-2020-106264 
Johnson, N., Veletsianos, G., and Seaman, J. 2020. U.S. faculty and administrators' experiences and approaches in the early weeks of the COVID-19 pandemic. Online Learning 24(2):621. https://doi.org/10.24059/olj.v24i2.2285

Kanuka, H. 2008. Understanding e-learning technologies-inpractice through philosophies-in-practice. In: Anderson, T., ed. The theory and practice of online learning. Edmonton, Alberta: AU Press. 91-118.

Kincheloe, J.L. 2005. Critical constructivism. New York: Peter Lang.

Lange, E.A. 2018. Transforming transformative education through ontologies of relationality. Journal of Transformative Education 16(4):280-301. https://doi.org/10.1177\%2F1541344618786452

Legg, T.J., Adelman, D., Mueller, D., and Levitt, C. 2009. Constructivist strategies in online distance education in nursing. Journal of Nursing Education 48(2):64-69. https://doi.org/10.3928/01484834-20090201-08

Leigh, J., Vasilica, C., Dron, R., Gawthorpe, D., Burns, E., Kennedy, S., Kennedy, R., Warburton, T., and Croughan, C. 2020. Redefining undergraduate nurse teaching during the coronavirus pandemic: Use of digital technologies. British Journal of Nursing 29(10):566-569. https://doi.org/10.12968/bjon.2020.29.10.566

Long, K.C. 2017. E-learning, information technology, and student success in higher education. Business and Management. Oxford Research Encyclopedias.

https://doi.org/10.1093/acrefore/9780190224851.013.78

Makokis, L. 2009. Disordered dependencies: The impact of language loss and residential schooling on Indigenous peoples. Rural Social Work and Community Practice 14(2): 6-11.

Malbeuf, J. 2018. Feds say all N.W.T. communities have highspeed internet, residents disagree. CBC News, May 18. https://www.cbc.ca/news/canada/north/federalannouncement-high-speed-internet-residents diasgree-1.4668223

Marshall, J., Roache, D., and Moody-Marshall, R. 2020. Crisis leadership: A critical examination of educational leadership in higher education in the midst of the COVID-19 pandemic. International Studies in Educational Administration 48(3):3037.

McBride, B. 2020. No Northwestel commitment on internet overage charges after April. NWT News/North, April 9.

https://nnsl.com/yellowknifer/northwestel-mum-on-internetoverage-charges-after-april/

NNSL Staff. 2019. NWTel working on unlimited internet, underwater fibre line - but don't hold your breath. NWT News/ North, October 8.

https://nnsl.com/yellowknifer/nwtel-working-on-unlimitedinternet-underwater-fibre-line-but-dont-hold-your-breath/

McNamee, T.Y., Willis, J., Ganss, K.M., Ardoin, S., and Sansone, V.A. 2020. Don't forget about rural higher education students: Addressing digital inequities during COVID-19. Diverse: Issues in Higher Education.

https://diverseeducation.com/article/176117
Mertens, D.M. 2003. The inclusive view of evaluation: Visions for the new millennium. In: Donaldson, S.I., and Scriven, M., eds. Evaluating social programs and problems: Visions for the new millennium. Mahwah, New Jersey: Lawrence Erlbaum. 91-108.

MNP LLP. 2018. Aurora College foundational review. Edmonton, Alberta: MNP LLP.

https://www.ece.gov.nt.ca/sites/ece/files/resources/aurora college_foundational_review_report_0.pdf

Moisey, S.D., and Hughes, J.A. 2008. Supporting the online learner. In: Anderson, T., ed. The theory and practice of online learning. Edmonton, Alberta: AU Press. 420-439.

Morley, C. 2008. Critical reflection as a research methodology. In: Liamputtong, P., and Rumbold, J., eds. Knowing differently: Arts-based and collaborative research. New York: Nova Science Publishers. 265-280.

__ 2014. Using critical reflection to research possibilities for change. The British Journal of Social Work 44(6):1419-1435. https://doi.org/10.1093/bjsw/bct004

Nowicka-Sauer, K., Jarmoszewicz, K., Trzeciak, B., Roszak, K., Zemla, A., Beta, S., Gutknecht, P., and Siebert, J. 2018. Constructivism in patient education: Using drawings to explore preconception of coronary artery disease. Kardiolgia Polska/Polish Heart Journal/ 78(8):1274-1276. https://dx.doi.org/10.5603/KP.2018.0165

Nutton, J., Lucero, N., and Ives, N. 2020. Relationality as a response to challenges of participatory action research in Indigenous contexts: Reflections from the field. Educational Action Research 28(1):100-111.

https://doi.org/10.1080/09650792.2019.1699132

NWT Bureau of Statistics. 2017. Indigenous peoples 2016 census. https://www.statsnwt.ca/census/2016/Indigenous_ Peoples_2016_Census.pdf

Ontario Ministry of Education. 2009. Realizing the promise of diversity: Ontario's Equity and inclusive education strategy. Toronto, Canada: Queen's Printer for Ontario. http://www.edu.gov.on.ca/eng/policyfunding/equity.pdf

Patel, V. 2020. Covid-19 is a pivotal moment for struggling students. Can colleges step up? The Chronicle of Higher Education, April 2014.

https://www.chronicle.com/article/covid-19-is-a-pivotalmoment-for-struggling-students-can-colleges-step-up/

Pidgeon, M. 2016. More than a checklist: Meaningful Indigenous inclusion in higher education. Multidisciplinary Studies in Social Inclusion 4(1):77-91. https://doi.org/10.17645/si.v4i1.436

Porr, C., and Egan, R. 2013. How does the nurse educator measure caring? International Journal of Nursing Education Scholarship 10(1):35-43.

https://doi.org/10.1515/ijnes-2012-0011

Preston, J.P. 2008. The urgency of postsecondary education for Aboriginal peoples. Canadian Journal of Educational Administration and Policy 86:1-23. 
Restoule, J.-P., Mashford-Pringle, A., Chacaby, M., Smillie, C., Brunette, C., and Russel, G. 2013. Supporting successful transitions to post-secondary education for Indigenous students: Lessons from an institutional ethnography in Ontario, Canada. International Indigenous Policy Journal 4(4):1-10. https://doi.org/10.18584/iipj.2013.4.4.4

Ross, A., Dion, J., Cantinotti, M., Collin-Vezina, D., and Paquette, L. 2015. Impact of residential schooling and of child abuse on substance use problem in Indigenous Peoples. Addictive Behaviors 51:184-192. https://doi.org/10.1016/j.addbeh.2015.07.014

Schön, D.A. 1987. Educating the reflective practitioner: Toward a new design for teaching and learning in the professions. San Francisco, California: Jossey-Bass.

Tamtik, M., and Guenter, M. 2019. Policy analysis of equity, diversity and inclusion strategies in Canadian universities How far have we come? Canadian Journal of Higher Education 49(3):41-56. https://doi.org/10.7202/1066634ar

Torres, M.G., Buck, C., and Gouldin, C. 2020. Making the leap from the traditional to the virtual educational experience. Boston, Massachusetts: New England Board of Higher Education.

https://nebhe.org/journal/making-the-leap-from-thetraditional-to-the-virtual-educational-experience/
TRCC (Truth and Reconciliation Commission of Canada). 2015. Truth and Reconciliation Commission of Canada: Calls to action. Winnipeg, Manitoba: TRCC.

http://nctr.ca/assets/reports/Calls_to_Action_English2.pdf

UNESCO (United Nations Educational, Scientific, and Cultural Organization). 2008. Inclusive education: The way of the future. International Conference on Education, 48th session, Final Report. Geneva, Switzerland: UNESCO.

http://www.ibe.unesco.org/fileadmin/user_upload/Policy Dialogue/48th_ICE/General_Presentation-48CIE-English.pdf

UN Human Rights Council. 2016. The promotion, protection and enjoyment of human rights on the internet. Resolution adopted on 18 July 2016. https://www.refworld.org/docid/57e916464.html

Weimer, M. 2020. Teaching in troubling times. The Teaching Professor, March 24.

https://www.teachingprofessor.com/covid-19/teaching-introubling-times/

Williams, O. 2019. It's vandalism, again. Police investigate new internet outage. Cabin Radio, August 12. 